\title{
Fretting fatigue of zinc coated low carbon steel EN H320 M
}

\author{
A. Ramalho *, L.M. Correia, J.D. Costa \\ Department of Mechanical Engineering, Polo II Campus, Coimbra University, 3030 Coimbra, Portugal
}

Received 10 April 1999; received in revised form 10 August 1999; accepted 9 August 2000

\begin{abstract}
The object of the present study was to investigate the influence of zinc coatings on steel sheets during fretting fatigue and fatigue tests. The influence of the fatigue stress range, normal pressure and amplitude of slip, on the fracture life was studied for both coated and uncoated EN H320 M steel. The wear produced by fretting was measured and compared with the fracture life evolution for different values of slip amplitude. The wear scars and the fracture surfaces were examined by scanning electron microscopy to identify the degradation mechanism. Although zinc films do not influence the fatigue life of the tested steel, when fretting is superposed on to a fatigue stress the coating markedly improves the fracture life. (C) 2000 Elsevier Science Ltd. All rights reserved.
\end{abstract}

Keywords: Fretting; Fretting fatigue; Surface coatings

\section{Introduction}

Fretting fatigue damage is frequently observed in mechanical components such as bearings, bearing housings, gears and rotors. Riveted structural joints can also reveal fretting fatigue when subjected to dynamic loading.

The main effect of fretting is to reduce the life of systems subjected to superimposed fatigue and fretting loads. Fenner and Field [1] have shown that fretting reduces the crack initiation stage. In plain fatigue loading the initiation phase may account for $90 \%$ of expected life, whereas in fretting fatigue initiation can occur in the first stage [1-4].

The anti-corrosive properties of zinc-coated steel sheets has led to them being increasingly used, especially in automotive structures. Some studies have been carried out to understand the effect of the zinc film on contact mechanics and on the texture of plastically deformed sheets [5,6]. However, in spite of the research already done in this field, proper criteria for designing parts or structures, taking into account the fretting fatigue effect, have not yet been established for this kind of material. This work examines the effect of fretting on the fracture life of a low carbon steel that is used mainly

\footnotetext{
* Corresponding author.

E-mail address: amilcar.ramalho@mail.dem.uc.pt (A. Ramalho).
}

in automobile structures, emphasizing the role of electroplated zinc films. The effect of certain fretting parameters was also studied.

\section{Experimental details}

\subsection{Materials}

Experiments were performed on a sheet of commercial low carbon steel, widely used in automobile structures. The chemical composition and mechanical properties of the EN H320 M steel are shown in Table 1 and Table 2.

The steel was tested both uncoated and coated with a thin zinc film. The coating was electrolytically deposited and was produced in industrial conditions. The zinc films were $5 \mu \mathrm{m}$ thick, and had a microhardness of 131 $\mathrm{HV}_{0.025}$.

\subsection{Fatigue and fretting fatigue tests}

The main aim of this study was to establish the effect of zinc films on plain fatigue behavior, in order to compare the results with those obtained with the same material when subjected to fretting fatigue. The fatigue study was performed using an Instron 1341 servohydraulic machine.

Fatigue tests were performed on control load, applying 
Table 1

Chemical composition of EN H320 M steel ${ }^{\mathrm{a}}$

\begin{tabular}{lllllllllll}
\hline Element & $\mathrm{Ceq}^{\mathrm{a}} \max$. & $\mathrm{Cmax}$. & $\mathrm{Mn} \max$. & Simax. & Pmax. & Smax. & $\mathrm{Al}$ & $\mathrm{Nb}$ & $\mathrm{Ti}$ & \\
\hline Weight\% & 0.21 & 0.08 & 0.70 & 0.35 & 0.025 & 0.030 & $0.02-0.08$ & $0.01-0.06$ & $0.01-0.10$ & $0.01-0.08$ \\
\hline
\end{tabular}

a $\mathrm{Ceq}=\mathrm{C}+(\mathrm{Mn}+\mathrm{Si}) / 6$.

Table 2

Mechanical properties of the EN H320 M steel

\begin{tabular}{ll}
\hline Tensile strength $\sigma_{\mathrm{UTS}}(\mathrm{MPa})$ & 459 \\
Yield stress $\sigma_{\mathrm{YS}}(\mathrm{MPa})$ & 352 \\
Elongation to break $\varepsilon(\%)$ & 53 \\
\hline
\end{tabular}

a constant amplitude load with a sinusoidal waveform, with a frequency of $25 \mathrm{~Hz}$ and a stress ratio $R=0.01$. The stress range varied from 310 to $385 \mathrm{MPa}$.

Fretting fatigue tests were carried out with the same test machine but using an apparatus specially developed to produce a fretting effect superposed on the fatigue stress. This apparatus, shown in Fig. 1, uses four rods to guide a set of plates supporting the fretting pads and a set of springs that apply and maintain the normal load. A pair of fretting bridges is used to apply normal pressure to cyclically stressed specimen surfaces. The pads used on the fretting bridges have squared edges and flat end form. The microslip of the fretting pads in relation to the specimen results from specimen elongation. The

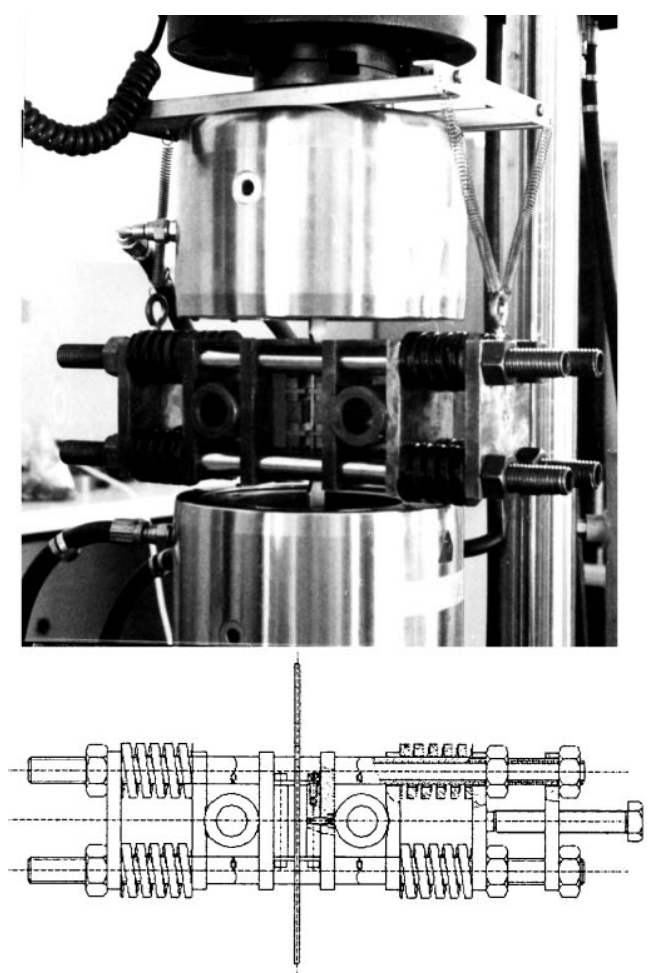

Fig. 1. Experimental apparatus. theoretical elongation depends on the fatigue stress range $\Delta \sigma$ and the distance between the pad pair $L$, by equation:

$\Delta L=L \frac{\Delta \sigma}{E}$

where $E$ is the Young's modulus, $\Delta \sigma$ the nominal value of the amplitude of applied cyclic stress and $\Delta L$ the specimen elongation when the fretting pads were at distance $L$.

The aim of the study was to evaluate the role of zinc coatings on fretting fatigue behaviour. Tests were therefore performed using a parametric approach. Fretting fatigue damage and the specific effects of normal pressure, fatigue stress and fretting amplitude were assessed by means of three groups of tests. Table 3 summarizes the ranges of the parameters studied, as well as the values of other test parameters.

The topography of the wear scars resulting from the fretting fatigue tests was evaluated using a Rodenstock RM600 laser profilometer. Depth profiles were acquired across the wear scars in the slide direction, and these were used to evaluate the transversal area of the wear tracks.

The morphology of the wear surfaces was observed using optical and scanning electron microscopes.

In order to evaluate the effect of zinc coatings, the study compared the results obtained for the coated and uncoated specimen pairs.

\section{Results}

\subsection{Surface roughness}

The surface roughness of the zinc films, and the substrate prior to deposition, was measured using a laser measuring system and a procedure that complied with with ISO standards [7]. Since it does not seem that measurement direction has any influence, the roughness was measured in random directions. Similar roughness values were obtained for both the fatigue specimens and fretting pairs. Table 4 shows the mean values and standard deviations for the roughness parameters: $R_{\mathrm{a}}, R_{\mathrm{z}}$, $R_{\mathrm{pm}} / R_{\mathrm{z}}$ ratios, and also the material ratio curve related parameters $R_{\mathrm{k}}, R_{\mathrm{pk}}$ and $R_{\mathrm{vk}}$.

The roughness values measured on both coated and uncoated specimens, presented in Table 4, reveal that the 
Table 3

Test parameters

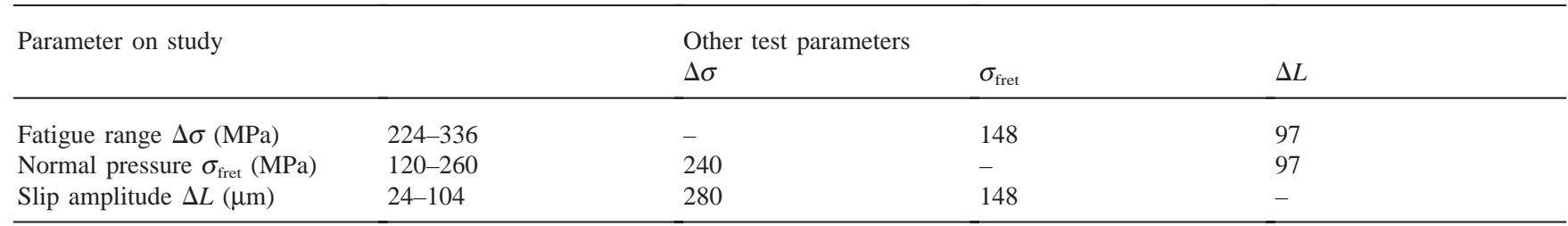

Table 4

Mean values and standard deviations of surface roughness

\begin{tabular}{llrrrrr}
\hline & $R_{\mathrm{a}}(\mu \mathrm{m})$ & $R_{\mathrm{z}}(\mu \mathrm{m})$ & $R_{\mathrm{pm}} / R_{\mathrm{z}}$ & $R_{\mathrm{k}}(\mu \mathrm{m})$ & $R_{\mathrm{pk}}(\mu \mathrm{m})$ & 0.86 \\
Zinc coating & $1.07(0.14)$ & $8.81(1.48)$ & $0.37(0.09)$ & 2.97 & $R_{\mathrm{vk}}(\mu \mathrm{m})$ & 1.79 \\
Substrate & $1.38(0.14)$ & $10.95(0.67)$ & $0.37(0.04)$ & 3.63 & 1.21 & 2.57 \\
\hline
\end{tabular}

electroplated zinc film smooths the steel surface. In fact, all three parameters, $R_{\mathrm{k}}, R_{\mathrm{pk}}$ and $R_{\mathrm{vk}}$, decrease to a similar extent, and the same value for the $R_{\mathrm{pm}} / R_{\mathrm{z}}$ ratio was obtained before and after the coating. The zinc film thus grows on the surface, maintaining the form of the surface irregularities. The zinc deposition does, however, produce a slight decrease in the height of the profile roughness.

\subsection{Fatigue}

Fatigue tests were carried out on both the coated and uncoated specimens, using the test conditions specified in Table 3. Fig. 2 gives the results of tension fatigue tests on the two types of specimen. The nominal stress range is plotted against the number of cycles to fracture. On the same graph, the lines and respective equations obtained by linear regression of the experimental results are plotted. Although the number of the tests performed was small, there is no doubt that a fatigue strength limit is demonstrated for both coated and uncoated materials.

In Fig. 3 the fatigue results of coated and uncoated steel are compared. Despite some scattering observed in the results, it appears that the zinc film does not produce any significant effect on lifetime.

Fatigue tests, whose results are presented in Fig. 2 and Fig. 3, reveal that the zinc electroplated films do not

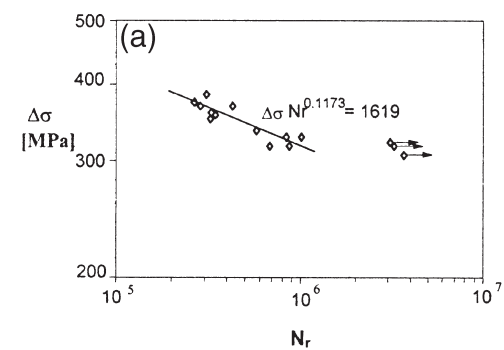



Fig. 3. Comparison of fatigue behavior of coated and uncoated specimens.

produce a significant change in the fatigue life of EN H320 M steel. The different results found in the literature lead to the conclusion that, in general, the deposition of soft materials makes no difference in fatigue behavior with respect to the substrate, while hard coatings can decrease fatigue life, to a greater or lesser degree [8].

\subsection{Fretting fatigue}

\subsubsection{Fatigue stress range}

To find the constant slip amplitude, independent of the axial fatigue stress, different distances between the

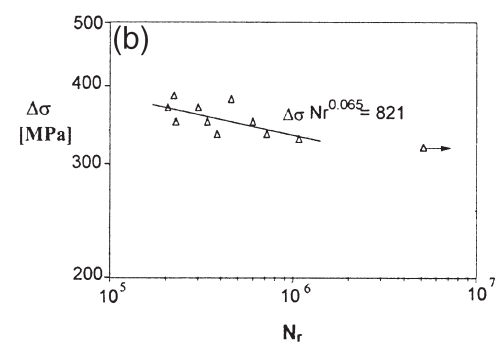

Fig. 2. Variation of fatigue life with nominal stress range. (a) Uncoated steel; (b) zinc coated steel. 

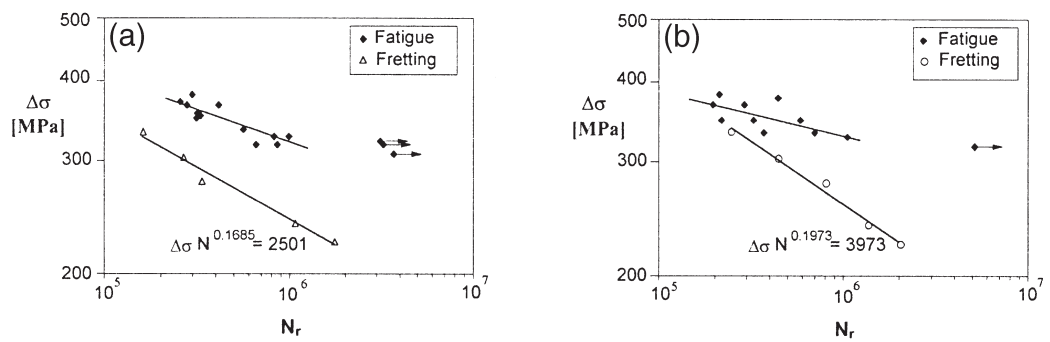

Fig. 4. Variation of fretting fatigue life with fatigue stress range. (a) Uncoated steel; (b) zinc coated steel.

pads of the fretting bridge were used for each value of the fatigue load range.

Fig. 4 summarizes the effects of the fatigue stress range on the fretting fatigue lifetime of both the zinc coated and uncoated substrates. The regression curves are also shown.

The superimposition of fretting to fatigue leads to a significant reduction in lifetime for both states. However, for the lower stress values the zinc-coated specimens show only a slight decrease in lifetime when compared to the fatigue tests (without fretting). The electrodeposition of the zinc films increases the fretting-fatigue life for all the values of the fatigue stress range studied (Fig. 5).

Tests performed on both coated and uncoated EN H320 M steel show that fretting fatigue promotes a marked reduction in lifetime compared with fatigue tests. When represented in a double logarithmic plot, the fretting fatigue life decreases linearly with the value of the fatigue stress range. The detrimental effect of fretting is more important at low fatigue stress levels, since the fretting effect promotes a decrease in the crack initiation period, and this initiation phase is already very low for high fatigue stresses. These results agree very well with those presented by Reeves and Hoeppner [9], and with other findings reported for different materials $[10,11]$.

\subsubsection{Normal pressure}

One series of fretting fatigue tests was carried out with different normal loads applied to the pads in order to

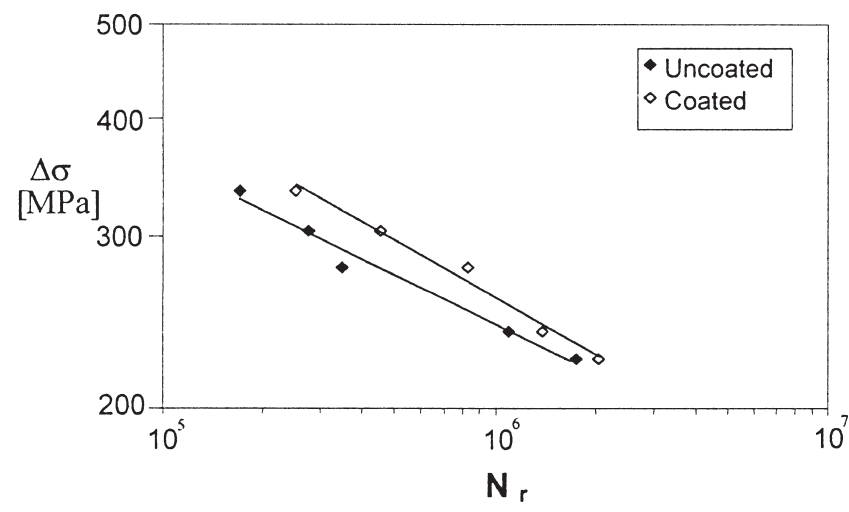

Fig. 5. Effect of zinc coating on fretting fatigue life. produce a normal contact pressure ranging from 120 to $260 \mathrm{MPa}$.

Fig. 6 presents the main results on the effect of normal load on the fretting fatigue life of the coated and uncoated steel specimens. It can be seen that the normal load does not have much influence on lifetime. However, some variation was observed for the uncoated steel when tested with the highest normal pressure value, while the coated specimens showed only a slight increase for the lowest normal pressure value.

The tests performed to evaluate the effect of normal pressure (Fig. 6) allow us to conclude that, within the range investigated, normal loads do not significantly change fretting fatigue life. The findings reported in the literature lead to a different conclusion. Normal loading promotes a reduction in fretting fatigue life if a crack initiation criterion is applied [12,13], however, Abidnazari and Hoeppner [14] have proposed the concept of a normal pressure threshold value, beyond which no effect on life is produced.

\subsubsection{Effect of slip}

With the fretting device described above, the slip results from the elongation of the part of the specimen spanned by the pad-bridge. In addition to this part of the fatigue specimen, both the compliance of the rig and, of course, the friction force, determine the effective slip amplitude. Nevertheless, as the test rig used was a free system, without external rigid supports, and not provid-



Fig. 6. Effect of normal pressure on fretting fatigue life $(\Delta \sigma=280$ MPa, $\Delta L=97 \mu \mathrm{m}$ ). 
ing friction measurements, the actual value of slip amplitude could not be obtained.

In order to change the relative displacement of the fatigue specimen length spanned by the fretting bridge a set of tests was carried out using fretting bridges with varying distances between the pads to obtain specimen elongation ranging from 24 to $104 \mu \mathrm{m}$.

Fig. 7 shows the experimental results of the influence of specimen elongation on the fretting fatigue lifetime, for both coated and uncoated materials.

The results allow us to conclude that there is a range of elongation values leading to a minimum on the fretting fatigue life. Fig. 7 shows three different areas on the graph where the elongation values that limit the three regions are not changed with zinc deposition. These three regions are:

$\Delta L<35 \mu \mathrm{m}$ : The lowest study value of slip displacement leads to high life values with similar magnitude for coated and uncoated pairs.

$35<\Delta L<65 \mu \mathrm{m}$ : The tests with specimen elongation within these limit values lead to the minimum life values. The zinc coating significantly increases lifetime.

$\Delta L>65 \mu \mathrm{m}$ : For elongation values greater than $65 \mu \mathrm{m}$ the fretting fatigue life increases and the zinc coated specimens show a higher life value than the uncoated ones.

Specimen wear was evaluated at the end of the tests by measuring the profile of the wear scar produced (Fig. 8 ). The wear contacts were measured for each specimen and the mean value of the transversal profile area was used. To compare the amount of worn material, if $\Delta L$ was used as an upper limit for sliding, a wear parameter $K(K=$ wear volume/[sliding distance $\times$ normal load]) was determined, resulting in the expression:

$K=\frac{A}{2 \Delta L N_{\mathrm{r}} B \sigma_{\text {fret }}}$

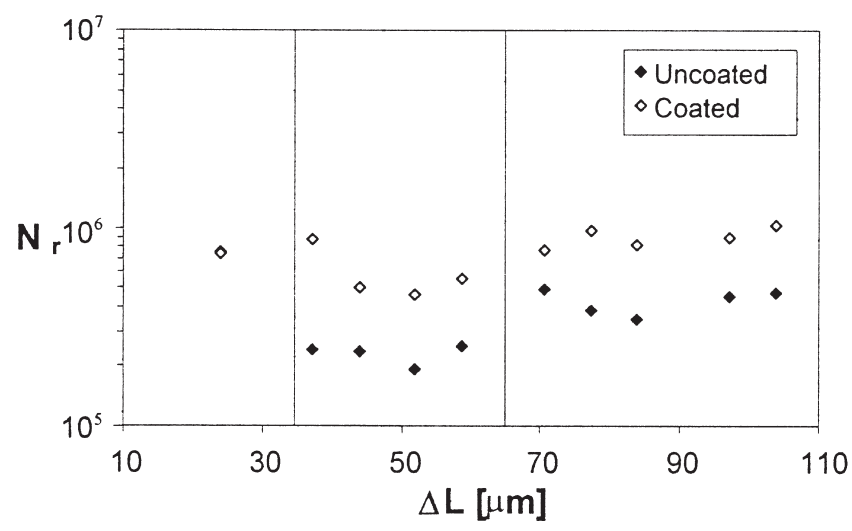

Fig. 7. Variation of fretting fatigue life with amplitude of elongation $\left(\Delta \sigma=280 \mathrm{MPa}, \sigma_{\text {fret }}=148 \mathrm{MPa}\right)$.

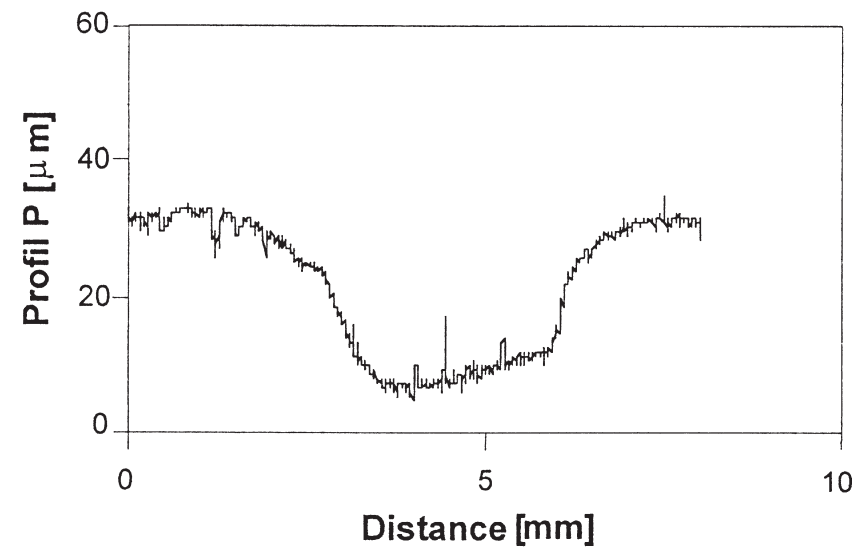

Fig. 8. Wear scar profile of an uncoated specimen $(\Delta \sigma=280 \mathrm{MPa}$, $\left.\sigma_{\text {fret }}=148 \mathrm{MPa}, \Delta L=97 \mu \mathrm{m}\right)$.

where $A=$ area of the transversal wear profile; $\Delta L=$ elongation; $N_{\mathrm{r}}=$ number of cycles to fracture in fretting fatigue; $B=$ thickness of the pad; $\sigma_{\text {fret }}=$ normal pressure.

Table 5 shows the mean values of the wear parameter, and Fig. 9 gives the plots of the wear coefficient against specimen elongation, superposed onto the fretting fatigue life.

The evolution of the wear coefficient $K$ confirms the three regions previously defined, and the same limiting values for elongation. The intermediate region, where the minimum life was obtained, now shows the maximum wear coefficient values. The zinc film leads to a great drop in wear values for all slip amplitude values, mainly in the minimum lifetime region.

As is widely accepted, the amplitude of slip seems to be the most important parameter determining fretting behavior. The results obtained, especially regarding the lifetime changes with slip amplitude, agree very well with those published by Vingsbo and Soderberg [15]. A typical change in lifetime with slip amplitude is characterized by three regions and is best studied using spherical contact, a situation that has been analyzed by Mindlin [16]. This evolution is determined by different regimes of interaction between the contact surfaces, namely, stick regime, mixed regime and gross slip regime. In this work, the amplitude of slip values that determines the transition between the different regimes seems to be greater than those published by other authors [15]. However, as explained above, the value used in this work is not the actual slip amplitude, but a greater value, based on the deformation of the specimen length between the fretting pads. The apparatus used for this work could not measure the friction force, making it difficult to explain the transition between the different regimes.

\subsection{Morphology of wear scars and fracture surfaces}

In order to understand the mechanisms of fretting fatigue damage, wear scars and fracture surfaces were 
Table 5

Effect of slip amplitude $\Delta L$ on wear $\left(\Delta \sigma=280 \mathrm{MPa}, \sigma_{\text {fret }}=148 \mathrm{MPa}\right)$

\begin{tabular}{|c|c|c|c|c|c|c|}
\hline$\Delta L(\mu \mathrm{m})$ & $\begin{array}{l}\text { Uncoated } \\
N_{\mathrm{r}}\left(\times 10^{5}\right)\end{array}$ & $A\left(\times 10^{4} \mu \mathrm{m}^{2}\right)$ & $K\left(\times 10^{-14} \mathrm{~m}^{2} / \mathrm{N}\right)$ & $\begin{array}{l}\text { Zinc coated } \\
N_{\mathrm{r}}\left(\times 10^{5}\right)\end{array}$ & $A\left(\times 10^{4} \mu \mathrm{m}^{2}\right)$ & $K\left(\times 10^{-14} \mathrm{~m}^{2} / \mathrm{N}\right)$ \\
\hline 24 & 7.6 & 12.9 & 19.8 & 7.5 & - & - \\
\hline 37 & 2.4 & 11.9 & 36.8 & 8.7 & 12.1 & 10.5 \\
\hline 52 & 2.0 & 12.6 & 35.1 & 4.6 & 10.2 & 12.0 \\
\hline 59 & 2.5 & 15.4 & 29.3 & 5.5 & 13.5 & 11.7 \\
\hline 71 & 4.9 & 11.1 & 9.1 & 7.7 & 11.2 & 5.7 \\
\hline 77 & 3.8 & 10.2 & 9.7 & 9.6 & 8.8 & 3.3 \\
\hline 84 & 3.5 & 10.0 & 9.6 & 8.2 & - & - \\
\hline 97 & 4.5 & 8.3 & 5.3 & 8.8 & 12.0 & 3.9 \\
\hline 104 & 4.7 & 11.7 & 6.7 & 10.3 & 10.0 & 2.6 \\
\hline
\end{tabular}



Fig. 9. Comparison of wear scar and fretting fatigue life for amplitude of elongation range from 24 to $104 \mu \mathrm{m}(\Delta \sigma=280 \mathrm{MPa}$, $\sigma_{\text {fret }}=148 \mathrm{MPa}$ ).

examined. Optical and scanning electron microscopes were used in morphology analysis.

Observation of fretting scars allows us to verify that the rupture results from crack initiation on fretting surfaces. However, different morphological features have been observed for coated and uncoated specimens. The contact surfaces of uncoated specimens mainly exhibit oxidation and some areas of adhesion. Fig. 10 shows an

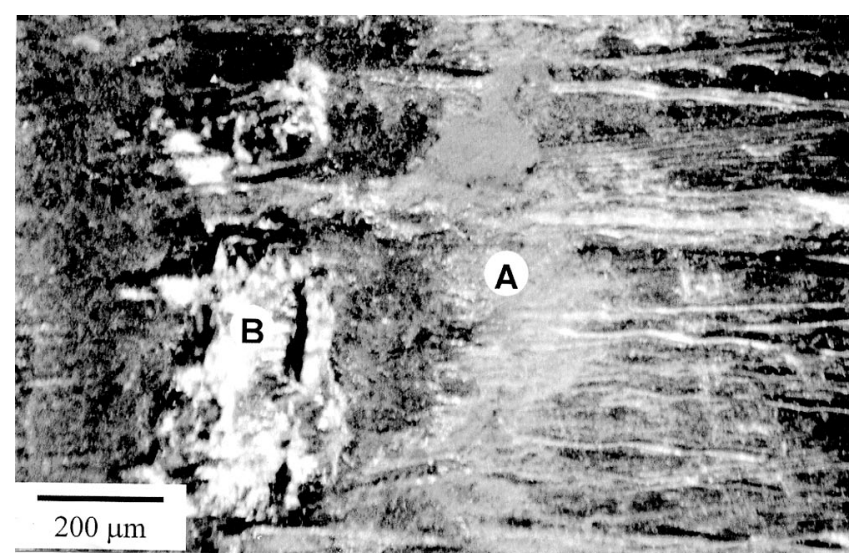

Fig. 10. Morphology of fretting surface of an uncoated contact. A, oxidation; $\mathrm{B}$, adhesion. optical observation of a typical uncoated contact surface, characterized by a central region with adherent material and a large amount of oxidation products at the marginal areas. Examination of the fret-damaged surfaces of electrodeposited zinc specimens shows smooth and clear surfaces with no evidence of iron oxide debris and no significantly severe adhesion-damaged areas (Fig. 11).

Although zinc films do not influence the fatigue life of the tested steel, when fretting is superimposed onto fatigue stress the coating markedly improves the lifetime. The steel tested in this study has a ferrite matrix, so the wear results mainly from transfer by adhesion and oxidation. Thus as zinc films inhibit the transfer process, perhaps producing friction reduction, they promote a significant increase in life. Gao et al. [17] have obtained an improvement in fretting fatigue resistance using low strength steel with Ni-P electroplated coatings, and Koul et al. [18] also report an improved effect due to mild $\mathrm{Cu}-\mathrm{Ni}-\mathrm{In}$ films for fretting fatigue applications.

Crack initiation often occurs at the limit of fret-damaged areas, although cracks can sometimes be initiated at the boundary between the central area and the margins of the fretted surfaces. The observation of non-fractured

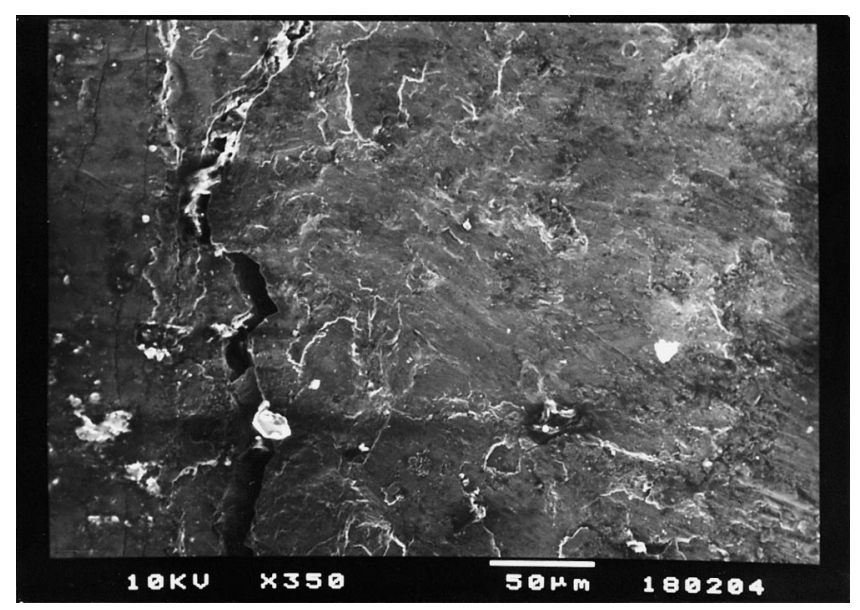

Fig. 11. SEM micrograph of fretting damaged surface of a zinc coated surface. 


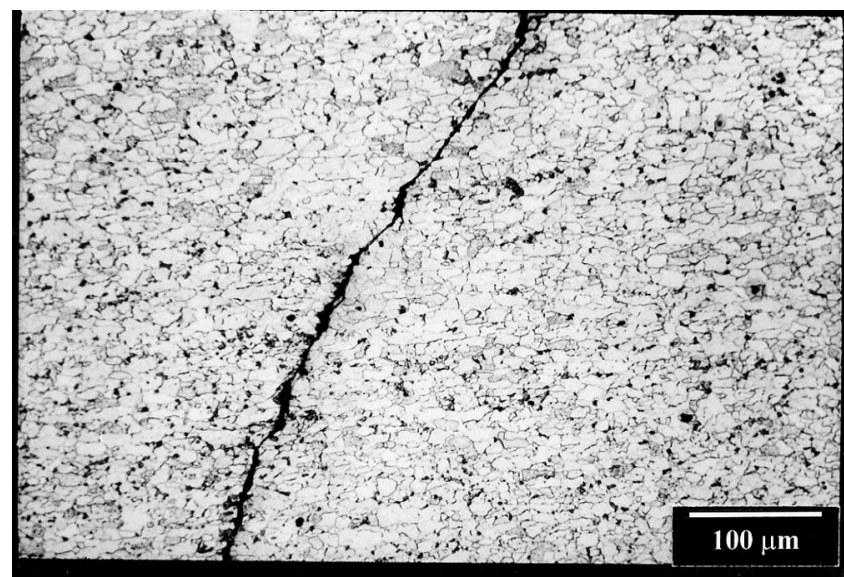

Fig. 12. Crack observation on the etched cross-section of an uncoated specimen.

surfaces (Fig. 12) reveals changes in crack propagation direction changes during the growing process. Three steps can be identified:

1. near the surface, the crack grows in normal direction related to the surface;

2. after a distance of some grains, propagation changes to a direction at roughly $45^{\circ}$;

3. far from the surface, the normal direction is re-established.

For both the coated and the uncoated pairs, the fracture surfaces always show a ductile striation fatigue mechanism (Fig. 13).

\section{Conclusions}

1. Zinc electroplated films do not produce a significant change in the fatigue life of EN H320 M steel.

2. Fretting fatigue promotes a marked decrease in life

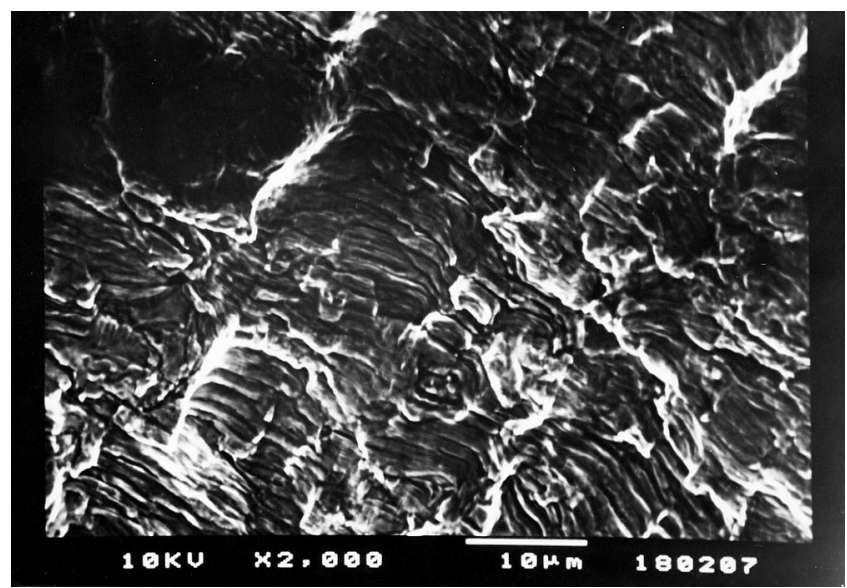

Fig. 13. SEM micrograph of the fracture surface of an uncoated fretting fatigue specimen. when compared with fatigue tests for coated and uncoated EN H320 M steel.

3. When fretting is superimposed onto a fatigue stress the zinc electrodeposited coating markedly improves the fracture life.

4. Increasing the slip amplitude promotes a change in life characterized by the sliding regimes in the three regions.

5. Wear scars on uncoated specimens comprise mainly oxidation and some adherent areas, whereas the electrodeposited zinc specimens show smooth and clear surfaces with no evidence of iron oxide debris, nor of significant severe adhesion-damaged areas.

\section{Acknowledgements}

The present work was supported by the Portuguese government Project Praxis XXI 2/2.1 TPAR 2041/95. L.M. Correia is grateful to the Portuguese Foundation for Science and Technology for funding their research work.

\section{References}

[1] Fenner AJ, Field JE. La fatigue dans les conditions de frottement. Rev Métall 1958;55:478-85.

[2] Nowell D, Hills DA. Crack initiation criteria in fretting fatigue. Wear 1990;136:329-43.

[3] Fellows LJ, Nowell D, Hills DA. On the initiation of fretting fatigue cracks. Wear 1997;205:120-9.

[4] Fouvry S, Kapsa PH, Vincent L, Dang Van K. Theoretical analysis of fatigue cracking under dry friction for fretting loading conditions. Wear 1996;195:21-34.

[5] Takaji M, Hasan M. Changes in surface texture of zinc-coated steel sheets under plastic deformation. Wear 1996;198:176-84.

[6] Takaji M, Hasan M. Contact mechanics of zinc-coated steel sheets. Wear 1996;199:260-7.

[7] ISO 13565-2:1996 Geometrical Product Specifications (GPS) Surface texture: Profile method; Surfaces having stratified functional properties - Part 2: Height characterization using the linear material ratio curve.

[8] Leis B. In: Fatigue and Fracture. ASM Handbook, vol. 19. Fatigue and Fracture, 1996:314-20.

[9] Reeves RK, Hoeppner DW. The effect of fretting on fatigue. Wear 1976;40:395-7.

[10] Endo K, Goto H. Initiation and propagation of fretting fatigue cracks. Wear 1976;38:311-24.

[11] Wharton MH, Taylor DE, Waterhouse RB. Metallurgical factors in fretting fatigue behavior of $70 / 30$ brass and $0.7 \%$ carbon steel. Wear 1973;23:251-60.

[12] Ruiz C, Boddington PHB, Chen KC. An investigation of fatigue and fretting in a dovetail joint. Exp Mech 1984;24(3):208-17.

[13] Nowell D, Hills DA. Crack initiation criteria in fretting fatigue. Wear 1990;136:329-43.

[14] Adibnazari S, Hoeppner DW. A fretting fatigue normal pressure threshold concept. Wear 1993;160:33-5.

[15] Vingsbo O, Soderberg S. On fretting maps. Wear 1988;126:131-47.

[16] Mindlin RD, Deresiewicz H. Elastic spheres in contact under 
varying oblique forces. J Appl Mech 1953;75:327-44.

[17] Gao H, Gu H, Zhou H. Effect of slip amplitude on fretting fatigue. Wear 1991;148:15-23.

[18] Koul AK, Xue L, Wallace W, Bibby M, Chakravarty S, Andrews
RG, Patnaik PC. An investigation on surface treatments for improving the fretting fatigue resistance of titanium alloys. In Proceedings of the 82nd Meeting of AGARD/SMB, Sesimbra, 1996:5.1-9. 